ANNIVERSARY ADDRESS.

\title{
ANNIVERSARY ADDRESS OF THE PRESIDENT.
}

\author{
CHARLES DAUBENY, M.D., F.R.S., \&c.
}

\section{Gentlemen,}

At our last Anniversary Meeting, I took occasion to descant upon the advantages that might accrue to science from the juxta-position of the different chartered Societies devoted to this object, in some convenient and central locality.

You may recollect my having then stated, "that I for one should heartily hail the day, which might witness the assemblage of all the principal Bodies dedicated in this place to the study of Nature under one and the same roof, pursuing their separate labours indeed independently, but at the same time deriving mutual support and assistance from their contiguity ; exercising over each other no paramount jurisdiction, but moving onwards in harmony and concert, as became the federal members of the great Republic of Science."

My opinions with regard to the desirableness of such an arrangement have since that period by no means undergone a change; nor am I aware that, in expressing the above sentiments on the occasion referred to, I said anything in which the great body of the Society over which I presided would not, at the time, have heartily concurred. Nevertheless, since we last met, circumstances have transpired with respect to the views of Government, in relation to the mode of carrying out the object alluded to, to which I confess myself as little able to assent, as any other of our Members can be.

It appeared from certain remarks which fell from the late 
Chancellor of the. Exchequer, in a speech delivered by him in the course of the preceding session, that it was then in the contemplation of Government to purchase a piece of land at Kensington Gore, partly under the expectation, that the chartered Scientific Societies of the Metropolis would accept as a boon the offer of any suitable suite of apartments which might be there erected at the public expense, as being a mode of realising a project, in which, it was presumed, that they all entertained a common interest.

Now, as a general repugnance was felt throughout the Societies referred to, to a removal to so distant a locality, it seemed necessary, that whilst we expressed, as in duty bound, our acknowledgments for the liberal disposition towards Science evinced by her Majesty's Government, we should at the same time, one and all, in order to prevent misapprehension, intimate our dissent to the particular scheme, by which our interests were thought to be consulted. And with regard to this Society in particular, I am persuaded, that the difficulty which most of our Members would find in resorting to so remote a part of the suburbs, for the purpose of attending our Meetings, would greatly counterbalance any advantage that might accrue from the gratuitous supply of apartments, even if by so doing we could hope to bring about that general juxta-position of scientific bodies, which we are all agreed to consider as desirable.

But it could not be forgotten, that three at least of the Societies included in this proposed arrangement are already provided with gratuitous accommodations in a central part of London, and are therefore less likely, even than ourselves, to consent to a removal to a more distant locality.

Without, therefore, presuming to anticipate what may be deemed convenient or advantageous hereafter, when perhaps the tide of population may roll westward, and the facilities of communication between distant parts of the metropolis may be increased, the Council deemed that they were not stepping beyond their proper functions, in protesting at the present time against the contemplated removal; and with this intent, directed me, as their President, to state to the Royal Society, in reply to a minute of the Council of that Body, having reference to this proposition, "that whilst they are ready to aid in promoting a practicable scheme, for the juxta-position of the said Scientific Societies, they are decidedly of opinion, that a removal of their library and place of meeting to Kensington would be seriously detrimental to the interests of the Chemical Society."

It will give me sincere pleasure to find, either that this or some future Government may be sufficiently alive to the importance of 
Physical Science, and sensible of the disadvantages under which it struggles in this country through the dispersed state of the Societics formed for its cultivation, to provide us all with some central and convenient establishment, where we can pursue our labours in common; but until this day arrives, let us be encouraged by recollecting what our predecessors in the same field have accomplished without such extraneous aid, and what it may be possible, therefore, for us also to achieve by our own unassisted efforts.

Of this, indeed, the illustrious chemist who has been lost to us since our last Anniversary-I mean Dr. Thomas Thoms on of Glasgow-affords us, as I conceive, one of the most instructive examples.

In early youth, not only without any of those appliances which some chemists, at least in forcign lands, have derived from their respective governments, but even without any further scientific training than what he could obtain from the public courses of lectures delivered at Edinburgh ; in spite, too, of restricted means, and the absence of private patronage, he gradually raised for himself a reputation for extensive knowledge, which placed him in the first rank amongst the cultivator's of his own particular Science. Indeed if amongst the chemists of the last generation, Dr. Dalton stood pre-eminent for the comprehensiveness of his generalisations, and Sir Humphry Davy for the brilliancy of his discoveries, Dr. Thomson may be regarded as holding the foremost place for his acquaintance with the facts of the Science, his careful digest of all that was then known in its several branches, and his impartiality in assigning to each contributor his appropriate share of merit.

At a time when no Treatise on Chemistry worthy of the name existed in Great Britain-when the greater part of what had been known in this country was obtained through the medium of translations from foreign languages, and when the facts recorded were put before us, often without much attempt at method or logical precision-Dr. Thom son surprised the world at an early age, by the publication of a System, in which the substances that came under his review were classified and arranged in such a manner, as to denote their mutual relations, and to exhibit the due subordination of their properties one to the other.

It may be doubted indeed, whether for the purposes of study, the analytical method of imparting knowledge, which he preferred adopting, is the one most advisable; it would rather seem, that instead of following, as he has done in his Treatise, the order of discovery, it might be better to commence with a statement of the gencral principles of the Science, and afterwards to enter in detail 
upon the properties of the individual substances, whose phenomena have guided our predecessors to the general laws applicable to them all.

But admitting this as a defect in Dr. Thomson's arrangement, the clear and exact manner in which he reduced to order the facts scattered at the time he wrote over a thousand different publications, demands from us our warmest acknowledgments.

It may be difficult, indeed, to say, whether Dalton would have been able to establish the existence of those definite combinations between bodies upon which his Atomic Theory was mainly built, but for the laborious and accurate statements which Dr. Thomson had brought together in his Treatise, with respect to the composition of various salts. Nor ought it to be forgotten, that at the early period, when Wollaston received with hesitation, and Davy with ridicule, the theory which the penetration of Dr. Dalton had first pointed out, Thomson stood forward as its warmest advocate, and supported it with some of the most convincing of its proofs.

Nor were his services in diffusing knowledge confined to the accurate record of facts contained in his System of Chemistry. For nine years-namely from 1813 to 1822 - he conducted the "Annals of Philosophy," a Periodical in which he did not content himself with a mere publication of Essays on scientific subjects, communicated to him by others, or to a bare report of any new discoveries made in this or in other countries, but also introduced each year a Digest of the progress of Science in its various departments, in which the merits of each contributor were discussed with freedom, but always with perfect frankness, and with an entire absence of prejudice and party feeling.

In this undertaking, no less than in the first introduction of that system of symbolic writing which is now in common use amongst chemists, Dr. Thomson may be said to have pointed out two most efficient instruments for the advancement of his favourite Science.

The former proved the prelude to those comprehensive Reviews of the annual progress of Chemistry, which were for many years given to the world by Berzelius; the latter, after having been extended and improved by the distinguished Swede, found at length a general reception in the country in which it originated.

At a later period of his life, he published his "Attempt to establish the first Principles of Chemistry by Experiment," a work which was censured by Berzelius, with a severity stimulated, no doubt, by the opposition between the results therein arrived at, and his own; although there may be some ground for alleging, that our con- 
fidence in his accuracy is impaired by doubts as to the correctness of the data upon which he proceeded.

The work, however, must be allowed by all unprejudiced persons to exhibit marks of the most persevering industry, and to supply us with much valuable information.

For a candid review of its merits, I may refer you to Mr. Crum's excellent Sketch of the Life and Labours of Dr. Thomson, in which the author, without disguising the defects imputed to the treatise in question, or seeking to extenuate unduly certain errors which attach to the principle upon which the calculations in it are founded, successfully vindicates his former master from the charge of dishonesty, or at least of wilful carelessness in the conduct of his experiments, which had been most unfairly brought against him.

Whilst, however, I willingly leave this part of the subject in abler hands than my own, I cannot refrain from adding, that his adoption, in the work in question, of Dr. Prout's ingenious suggestion, that all other bodies were multiples of hydrogen, seems at length, notwithstanding the adverse verdict of the great Swedish chemist alluded to, and of others respecting it, borne out with regard to oxygen, carbon, azote, and calcium, by the elaborate researches of Dumas and Marignac, whilst other experimentalists appear to have since successfully reduced sulphur, zinc, silver, mercury, and iron to the same standard.

And when we recollect, on the one hand, how numerous are the sources of error which may creep into the best devised series of experiments, and, on the other, how infinite are the chances against our arriving, by any erroneous and therefore fortuitous results, at numbers which turn out to be exact multiples of the atomic weight of hydrogen, the argument in favour of Prout's doctrine, founded upon the coincidence of the figures in the cases above cited, seems greatly to exceed in strength that which can be alleged against it, from the non-accordance between experiment and calculation in the instance of a few other elementary bodies.

As an Historian of Science also, Dr. Thomson's merits were of a high order, from his candour, frankness in expressing his opinion, and diligence in ascertaining facts; indeed, his biographical notices supply us with some of the most valuable records we possess, with respect to the lives and characters of Chemists in this and the last century.

As Professor of Chemistry at Glasgow, an appointment which he held from the year 1818 till the period of his death in the summer of last year, Dr. Thomson had the satisfaction of training many who 
have done honour to the school which he instituted, either by their scientific, or their practical contributions to Chemistry. Need I mention the names of Graham, of Walter Crum, Hugh Colquhoun, Alexander Harvey, Johnston of Durham, of Clark, and of Stenhouse, as exemplifications of this fact; or remind you that my only motive for passing so lightly over this portion of Dr. 'Thom son's services is the fear of offending the modesty of some of his surviving pupils who may chance to be present?

I cannot, however, terminate these remarks, without observing, that the career of Dr. Thomson affords to the young chemist a cheering proof of the advances that may be made in Science, even under great original disadvantages, by an understanding, solid rather than brilliant, and marked more by sagacity and common sense than by genius and originality ; provided only these powers of mind are, as his were, concentrated through life upon certain special objects, and are stimulated into exertion by no more selfish and ignoble principle than the pure love of scientific truth.

We have also lost since our last Anniversary, Mr. John Sylvester, a gentleman eminent for his successful applications of the Science of Engineering to domestic purposes. He was the son of Mr. Charles Sylvester, the well-known author of the "Philosophy of Domestic Economy," the principles of which he applied with so much sagacity in the case of the Derby Infirmary, as thereby to establish his reputation as a civil engineer. It was no doubt in great measure to the attentive study of his father's theory and practice, that we may attribute the expertness which our late Fellow displayed in the execution of large works for warming and ventilating buildings, as well as the success which attended some of his inventions, as in the case of the Radiating Stove Grate, now in such general use.

Mr. Sylvester was particularly happy in his contrivances for warming the Arctic Discovery ships, sent out under Captains Parry, Ross, and others; and it is said that the Ridge and Furrow Roof, so successfully applied by Sir Joseph Paxton to the Crystal Palace, had been previously adopted by Mr. Sylvester in the forcing houses he constructed for Mr. Strutt of Derby, in the year 1844. He was also an accomplished amateur-draughtsman, and was much regretted by his personal friends for his many amiable qualities.

His decease in the August of last year was occasioned by an obscure complaint, from which he had for a considerable time been a sufferer. 
In vacating the Chair, which I have had the honour to occupy during the last two years, I am happy to think I am leaving the Society in a satisfactory state, both as regards its present condition and its future prospects.

We have, indeed, at two or three of our Meetings been left without a supply of matter, an accident more likely to occur in a Chemical Society than in one of a more miscellaneous and discursive character; and, indeed, when we reflect how many bodies, medical, pharmaceutical, and agricultural, divide with us the fruits of the labours which are carried on by chemists, not to speak of the number of chemical papers, which, as I remarked in my last Address, are communicated by us to the Royal Society, and appear in its Transactions, we need not be surprised if the supply of matter has not always kept pace with the activity of our Members, or with the interest which the Science is exciting in the mind of the public.

The flow of original communications has indeed of late been somewhat of an intermittent character, sometimes copious, sometimes deficient; but it is but fair to add, that whenever a void has occurred at our Meetings, it has been so well filled up by discussions of a general scientific interest, as to leave to those who attended. little reason to regret that no new series of researches had been submitted to them on those occasions.

Our Members, however, ought not to forget, that this Society has the first claim to the services and contributions of those enrolled in it ; and that, even if the researches they are carrying on seem of that practical or technical character as to dernand, in the first instance, a different destination, it may be for the mutual advantage of themselves and of the Society that they should be subsequently submitted to us, as the merits of the scientific principles they involve are nowhere likely to be so satisfactorily or so fully canvassed as at the Meetings beld in this room.

It is, moreover, a subject of regret to me, that nothing should have been done during my Presidentship, either by myself or others, towards simplifying and methodising the existing nomenclature of organic substances, which at the present time seems to proceed upon no fixed basis, or, at least, is guided by such rules only as may exist floating in the minds of the leading chemists who have most advanced this part of their Science, and which have never yet been distinctly enunciated. In a communication made to the chemical lecturer of the British Association at Ipswich, two years ago, I took occasion to point out what those rules apparently were, so far as 
could be gathered from the practice of the individuals alluded to; and by so doing, may perhaps flatter myself with having contributed somewhat, towards promoting that uniformity and consistency in the use of the terms selected for designating newly-discovered compounds, which is in many respects so desirable.

But the larger and more ambitious scheme which I had once contemplated-that of enlisting the leading chemists of the country, and of this Society in particular, in the attempt to frame a general system of nomenclature, which might embrace the whole of Organic Chemistry-I have been induced to postpone, from considering the unsettled state of certain fundamental questions, upon which so much of the terminology as well as of the notation of organic bodies is necessarily dependant.

The Society is watching with interest the development of those views, which have more than once been brought before our notice, "On the condition of Elements at the moment of Chemical Change," views, which, if adopted, would tend to modify many of our ideas with respect to chemical or electric affinity; tending, as they do, to the conclusion, that the particles of an elementary body are held together, not by that force which we term cohesive attraction, but by a kind of chemical affinity brought about in them, as it is in the case of compound bodies, by certain differences in the electrical condition subsisting between their particles.

The ingenious speculations also of another of our colleagues, by the aid of which he explains in so novel a manner the theory of etherification, appear to be based upon a similar principle, inasmuch as, instead of that fixity which was supposed to be involved in the very idea of a stable and definite compound, they assume a constant movement amongst its particles, arising, as it should seem, from some difference in their electrical condition.

To such a view, indeed, I am myself the more reconciled, as it is quite in harmony with the speculations which $I$ ventured to indulge in at the time of the publication of the last edition of my Atomic Theory.*

I then remarked, that "if the particles, into which heat is capable of resolving matter, when it assumes the gaseous condition, be themselves divisible into still minuter ones under the influence of chemical affinity; and if even the latter, perhaps, are composed of groups of atoms, rather than of single ones, it is conceivable that every one of these groups, within its own little world, should admit of such an

* Introduction to the Atomic Theory, p. 278. 
alteration in the position of its respective particles, as may serve to affect the properties it possesses, and consequently its relations to other bodies; although no one of these particles can separate itself from the group, of which it constitutes a part."

This intestine movement amongst the particles of a solid body seems likewise confirmed by the phenomenon of allotropism, and by the change of form, colour, \&c., which occurs in many bodies after crystallization; whilst on a larger scale, the same is attested by many circumstances remarked by geologists with regard to the formation of mineral veins; the segregation of certain substances from the general mass of the containing rock; and other molecular changes which appear to be taking place within the bowels of the earth.

And since this mobility of particles is extended even to those which constitute the mass of a solid body, the theories of chemists in this respect seem tending to the same point as those of geologists, inasmuch as the former suppose a continual oscillation in the molecules of a body, owing to the interchange which is taking place between them; whilst the cosmogonists of the present day maintain the same with respect to the solid fabric of the globe, which their predecessors figured to themselves as the very emblem of stability.

The theory, however, which in the case before us is built upon this postulate, requires for its adoption such a revulsion in our ideas with respect to the relations between ether and alcohol, as would involve in the end a new nomenclature, as well as a fresh method of notation. We should be called upon to alter the atomic weights of all the other elements, by doubling the number of atoms of hydrogen assumed to be present in water; and instead of regarding ether simply as the oxide of an hydrocarbon, and alcohol as its hydrate, we should have to figure to ourselves the former as produced from water, by the replacement of one of its hydrogen atoms, and alcohol by that of both.

Such a view of the composition of these and other allied bodies has, indeed, much to recommend it, and deserves, in my humble opinion, the attentive consideration of chemists ; but it is one thing to receive a new theory with favour, and to entertain it with attention; and another to admit it so entirely into the category of established truths, as to mould all our other views in accordance with its principles.

In framing a system of chemical nomenclature, therefore, at the present moment, we should neither be justified in ignoring the existence of theories which have already taken a certain hold upon the minds of eminent chemists, both in this and in other countries; nor 
could we venture to propose them as the basis of our scheme, whilst still under discussion, and perhaps but imperfectly developed as yet even in the minds of the individuals who have promulgated them.

To discuss however, as they deserve, these and other theoretical views, which occupy so prominent a place in the Journal of our Society, would be impossible, without transgressing the limits which custom has hitherto assigned to your President's Anniversary Addresses.

Here, therefore, I might be inclined to pause : but lest it should be imagined that our Members are exclusively absorbed in the speculative departments of Chemistry, to the neglect of the practical, I will briefly allude to the important services rendered to the cause of agriculture by Professor Way, in the course of the various researches be has been carrying on in behalf of the Royal Agricultural Society; and especially by the manner in which he has elucidated the problem relating to the absorbent power possessed by different soils with reference to manures, and in which he has traced to its principles the property which belongs to Clay, of arresting in their downward progress the organic matters present in the water which percolates the earth, and even of separating from this solvent its most valuable saline contents-namely, the ammoniacal and other alkaline constituents with which it may be impregnated. And this, too, he has shown to be done by means of a double decomposition carried on in apparent contravention of the received laws of elective attraction. A discovery of this kind is not less important from its practical applications, than it is interesting in its bearings on the general principles of the Science; and although not announced in the pages of our Transactions, deserves to be mentioned as the fruit of the persevering researches of a chemist, who is enrolled in the list of our Fellows.

Nor will it, I hope, be deemed irrelevant for me to allude to the important application of Scientific Chemistry to the solution of certain Geological Problems, which has been carried out by one of the most distinguished of our Foreign Members.

Those who have taken the trouble of perusing my work on Volcanos, and especially the second edition of it, published in 1848, will recollect, that in bringing forward that theory which may be regarded as a revival, or perhaps a development, of the original hypothesis of Sir Humphry Davy, my professed object principally was that of enlisting the services of chemists in an attempt to elucidate a series of phenomena, which, although essentially chemical, had been hitherto, in a great degree, abandoned to geologists. 
Indeed, since the time when Gay-Lussac published his "Remarks on Vesuvius," and that at which Sir Humphry Davy paid a cursory visit to the same spot, no chemist of European reputation appears to have made volcanos a subject of study; excepting Abich, to whom we owe the first lucid sketch of the chemical relations which volcanic and plutonic rocks bear to each other; and Professor Bisch off of Bonn, whose researches were, however, confined to extinct volcanos, such as those of the Rhine and Eyfel.

Hence it is not to be wondered at, that the subject should be treated as though it were exclusively a mechanical problem, and theorised upon without any due appreciation of the interesting chemical phenomena which it presents to our notice.

It was this consideration more especially which led me, in my work on Volcanos, to give a prominence to those points which appeared to have been unduly neglected by others ; and to advocate with more zeal than I might otherwise perhaps have felt inclined to do, a theory, which necessarily brought before us the nature of the gaseous, saline, and crystalline products, which proceed from the internal focus of its action.

That this was my object, will appear from some remarks which I made fifteen years ago, in my "Report on Mineral and Thermal Waters," undertaken at the request of the British Association for the Advancement of Science, and published in their Transactions.

"We ought," I observed "carefully to distinguish between that which appears to be a direct inference from observed fact, and what can at most advance no higher claim than that of being a plausible conjecture. The general occurrence of volcanos in the neighbourhood of the sea, and the constant disengagement of aqueous vapour, and of sea-salt from their interior, are facts that establish in my mind a conviction that water finds its way to the seat of the aqueous operations, almost as complete, as if I were myself an eye-witness of another Phlegethon, discharging itself into the bowels of the earth, in every volcanic district, as in the solitary case of Cephalonia."

"Nor is the access of atmospheric air more questionable than that of water; so that the appearance of hydrogen united with sulphur, and of nitrogen either alone or combined with hydrogen at the mouth of the volcano, seems a direct proof, that oxygen has been abstracted by some process or other from both."

"Having satisfied our minds with regard to the fact of internal oxidation, we naturally turn to consider what principles can have existed in the interior of the earth capable of abstracting oxygen from water, as well as from air; and this leads us to speculate on the basis of 
the earths and alkalies, as having been instrumental in causing it. But in ascribing the phenomena to the oxidation of these bodies, we ought not to lose sight of the Baconian maxim, that in every well-established theory, the cause assigned should be not only competent to explain the facts, but also known to have a real existence, which latter circumstance cannot, of course, be affirned of the alkaline and earthy metalloids, as having a place in the interior of the earth."

I should not despair of being able to show that such an hypothesis is still tenable; but it will be more profitable on the present occasion, as well as, I doubt not, more agreeable to my hearers, for me to point out the substantial additions which Professor Bunsen has supplied to our knowledge of this class of phenomena.

He has, in the first place, proved that the products of volcanic action-at least as they display themselves in that vast focus of internal energy which we observe in the Island of Iceland-consist only of two kinds of material: either a trachytic rock, consisting of a trisilicate of alumina, conjuined with a similar compound of silica with an alkali or alkaline earth; or else an augite rock, in which 1 atom only of silica is combined with 2 atoms either of alumina, protoxide of iron, lime, magnesia, potass, or soda.

Bunsen has given a formula, by which the proportion between these two constituents, in any given rock, may be readily computed; and hence concludes, that the products of volcanic action in Iceland are derived from two independent foci.

But the most interesting part of his researches relates to the changes which have been wrought upon these materials by causes of subsequent operation.

Few of the friends I see around me on the present occasion are old enough to have witnessed the contests which for many years were waged with so much fury between the advocates of the igneous and aqueous origin of basalt.

In this controversy much stress, I recollect, was laid by the Wernerians on the characters of trap-tuff, which, it was contended, could by no means admit of being referred to the action of heat, whilst its passage into trap-rocks rendered it difficult to ascribe to the one an origin which was denied to the other.

Now, Professor Bunsen has, in the first place, beautifully shown that the species of tuff, which prevails in Iceland, and which is also abundant in Sicily, as is implied by its name Palagonite, derived from the village of Palagonia at the base of Etna, possesses such a chemical composition as identifies it with the pyroxenic rock of the neighbourhood. 
He has also suceeded in explaining those differences in structure and in appearance, which, in spite of this correspondence in the nature of its constituents, stamp it as a distinct mineral; having traced such alterations to the operation, not indeed of water alone, but of an alkali, or an alkaline earth, containing just so much water as to exist in the condition of a hydrate, formed in either case by the influence of a temperature equal to that of ignition.

The Professor states, that he has actually succeeded in converting basalt into palagonitic tuff, by mixing it in a state of fine powder with 13 times its weight of slaked lime, or of potass.

Thus, the very alkali, which may have been sublimed from some internal focus of igneous action, might, if water were also present, have been instrumental in converting an ordinary pyroxenic rock into palagonite under the influence of heat.

Another difficulty which besets the Huttonian theory, arose from the existence of zeolites in the midst of rocks of supposed igneous formation; as the readiness with which these minerals part with their water, seemed inconsistent with the supposition of their originating at a high temperature.

This was got over by supposing such minerals to have been formed under a pressure sufficient to prevent the water from escaping, and hence the Vulcanists were in some cases driven to assume pressure, where none could be shown to have existed.

But Bunsen has relieved them from this embarrassment, by demonstrating, that zeolites may be generated, by fusing lime and silica with an excess of caustic potass, without any pressure at all : and that by this method crystals may be produced at a red heat containing water, of which, however, the greater part is disengaged at a temperature not exceeding $228^{\circ}$, when the substance is detached from the crucible in which it had been formed.

Professor Bunsen has also, by a series of decisive experiments, removed all doubts as to the nature of the aeriform bodies which are disengaged from volcanos, and has fully substantiated, what my own observations, and those which I had collected from various other sources, led me to infer-namely, that inflammable gases, made up, either wholly, or in part of hydrogen, are amongst the most constant concomitants of volcanic action in all its various phases. Nitrogen also, often unaccompanied with oxygen, seems to be as common in the fumareles of Iceland, as I have found it to be in the thermal springs of other volcanic regions.

And with respect to the origin of these gases, Bunsen most satisfactorily refutes the idea of his countryman Bischoff, who refers them to the spontaneous decomposition, or dry distillation of organic 
matters, showing that when this process takcs place, nitrogen is invariably accompanied with marsh gas and other hydrocarbons which are never present in volcanos.

He accordingly expresses his decided opinion, that the objections which have been supposed to be fatal to the old volcanic theory of Davy, entirely lose their value after these results. "For if," he remarks, "in the spirit of this theory, it is assumed, that the lavas, and the phenomena of ignition accompanying them, result from an oxidation of alkaline and earthy metals, determined by a decomposition of water, it admits of being proved, that the quantity of the hydrogen evolved from volcanos, bears a perfect relation to the magnitude of the streams of lava formed."

A single one of the vapour springs of Krisuvik yields, according to Bunsen's own calculations, about 12 cubic metres of hydrogen in 24 hours.

" Assuming, then, that the remaining innumerable springs, together with the large fumaroles occurring there, yield together a quantity only 100 times as great-which may safely be regarded as far less than the quantity of this gas which is actually evolved-we may, by means of this assumption and simple calculation, show, that the formation of lava, which would be equivalent to such an evolution of gas within the period which elapses between two great eruptions, is sufficient to produce immense streams of lava."

"Nor is it any longer possible to attach importance to the second of the principal objections which have been made to Davy's hypothesis-namely, that it is unusual to observe any sensible appearance of flames during great volcanic eruptions. For if, from the known composition of the first-mentioned fumarole gas, we estimate the temperature of its flame, we find it to be $305^{0 .} 6$; consequently, a temperature which is far below the point of ignition of hydrogen. These gases are, therefore, combustible only at a red heat, and even under the most favourable circumstances can only produce by such a combustion an increase of temperature amounting to $305^{\circ} \cdot 6$, which in a red heat must necessarily escape altogether observation by the eye."

Satisfied with having obtained the weighty testimony of Professor Bunsen in favour of the facts which $I$ had alleged in confirmation of the theory to which I had given my adhesion, I shall the less regard the opposition that exists between my views and his with respect to the source of the hydrogen evolved.

Professor Bunsen derives this gas from the process in which pyroxenic lava is converted into palagonite through the agency of the 
hydrates of the alkalies or alkaline earths, assisted by a high tenperature, during which, as he has shown, hydrogen is evolved; and he even shows that if sulphur in vapour be brought into contact with basalt at a high temperature, and afterwards steam be passed over the rock so treated, sulphurous acid is disengaged in the first instance by the union of the sulphur with the oxygen of the peroxide of iron, which metal forms, with another portion of the same body, sulphuret of iron; and that sulphuretted hydrogen will be emitted in the second instance, owing to the decomposition of water, and the union of its hydrogen with the sulphur of the pyrites, whilst its oxygen forms, with the metallic portion, magnetic oxide of iron.

Supposing the formation of palagonite to be going on at all times when sulphuretted hydrogen and pure hydrogen can be shown to be concomitants of the volcanic action, and on a scale commensurate to the amount of gas generated, the explanation of Professor Bunsen will probably be accepted by chemists in general, in preference to that which refers it to the decomposition of water by alkaline and earthy metalloids, or their yet unoxidized sulphurets; but I cannot admit, as a valid objection to this latter hypothesis, the absence of carbonic oxide from volcanic exhalations of which carbonic acid constitutes so large a proportion. No doubt the latter would, as Bunsen remarks, be partially converted into carbonic oxide by hydrogen at the high temperature which probably exists around the focus of the volcanic action; but I have always been accustomed to refer the carbonic acid given off by volcanos to the diffusion of heat over contiguous limestone rocks, and not to processes going on at the point where the temperature was most intense.

Nor do I feel quite satisfied with the explanation offered by the Professor, of the presence of sal-ammoniac in the lava, which he refers to the vegetable matter existing in meadow-land overflowed by the molten current. If such were the origin of the volatile alkali, we ought not to find it exhaled round the orifices of the crater, or from any of the fumaroles proceeding directly from the same internal focus of action.

It is not my purpose, however, especially on such an occasion as the present, to criticise the labours of this eminent chemist, or to dwell upon those points in which the results of my own humbler inquiries in the same field of research may clash with his. It is sufficient for me to have pointed out to you his Memoirs on the subject of the Iceland Volcanos, as an important present rendered by Chemistry to the sister Sclence of Geology; and as a service too, 
which those who turn away with indifference from researches of a more refined nature, lying strictly within the domain of pure chemistry, would be likely to accept as an undeniable evidence of the extensive utility of our pursuits.

It is, indeed, a fortunate circumstance, in more respects than one, when such happy applications of chemical principles to other departments of natural knowledge are carried out by those of our brethren, who had before established their reputation amongst ourselves, by researches which chemists, and chemists only, are capable of appreciating.

No geologist, at least, can feel, that he has a right to impugn as visionary, conclusions, which have been deduced by a philosopher, who had before attained the first rank amongst experimentalists, by his profound and intricate investigations into the members of the Cacodyle series; just as for the same reason no candid mind can fail to pay deference to the suggestions of another of our foreign associates, on questions relating to physiology, agriculture, and the like; knowing, that before that eminent philosopher had turned his attention to these subjects, he had already earned a great name amongst chemists, by the success with which he had grappled with the most difficult problems in Organic Chemistry; and by the flood of light which he had shed over a class of bodies, before comparatively unattractive, owing to the obscurity which enveloped their real nature, and the absence of those connecting links, the discovery of which by himself, more than perhaps by any other single individual, has shown that they constitute the parts of one harmonious and unbroken series.

And now, Gentlemen, nothing more remains, except that I should express my most cordial thanks to you all, for the kindness and courtesy I have ever experienced since I began to fill the honourable office which you conferred upon me; and to the Members of the Council more especially for relieving me, as they have done, by their close attention to your affairs, from the most onerous portion of my duties. It is also satisfactory to me, on relinquishing the Chair, to reflect, that in selecting Colonel $\mathrm{Y}$ orke as my successor, you will place at your head a zealous Member of the Society, who, as being resident amongst you, will have the power, far more efficiently and more regularly than I have found myself able to do, of watching over your interests, and of presiding at your Meetings. 